\title{
Alterations in cytokines and haematological parameters during the acute and convalescent phases of Plasmodium falciparum and Plasmodium vivax infections
}

\author{
Rodrigo Nunes Rodrigues-da-Silva', Josué da Costa Lima-Junior', Bruna de Paula Fonseca e Fonseca ${ }^{2}$, \\ Paulo Renato Zuquim Antas ${ }^{3}$, Arlete Baldez ${ }^{4}$, Fabio Luiz Storer ${ }^{5}$, Fátima Santos ${ }^{6}$, \\ Dalma Maria Banic ${ }^{7}$, Joseli de Oliveira-Ferreira ${ }^{1 /+}$
}

\begin{abstract}
${ }^{1}$ Laboratório de Imunoparasitologia ${ }^{3}$ Laboratório de Imunologia Clínica ${ }^{7}$ Laboratório de Simulídeos e Oncocercose, Instituto Oswaldo Cruz ${ }^{2}$ Laboratório de Tecnologia Diagnóstica, Bio-Manguinhos-Fiocruz, Rio de Janeiro, RJ, Brasil ${ }^{4}$ Agência de Vigilância em Saúde, Secretaria de Estado da Saúde, Porto Velho, RO, Brasil ${ }^{5}$ Faculdade São Lucas, Porto Velho, RO, Brasil ${ }^{6}$ Odebrecht Energia/Usina Hidrelétrica Santo Antônio, Porto Velho, RO, Brasil
\end{abstract}

Haematological and cytokine alterations in malaria are a broad and controversial subject in the literature. However, few studies have simultaneously evaluated various cytokines in a single patient group during the acute and convalescent phases of infection. The aim of this study was to sequentially characterise alterations in haematological patters and circulating plasma cytokine and chemokine levels in patients infected with Plasmodium vivax or Plasmodium falciparum from a Brazilian endemic area during the acute and convalescent phases of infection. During the acute phase, thrombocytopaenia, eosinopaenia, lymphopaenia and an increased number of band cells were observed in the majority of the patients. During the convalescent phase, the haematologic parameters returned to normal. During the acute phase, P. vivax and P. falciparum patients had significantly higher interleukin (IL)-6, IL-8, $I L-17$, interferon- $\gamma$, tumour necrosis factor (TNF)- $\alpha$, macrophage inflammatory protein-1 $\beta$ and granulocyte-colony stimulating factor levels than controls and maintained high levels during the convalescent phase. IL-10 was detected at high concentrations during the acute phase, but returned to normal levels during the convalescent phase. Plasma IL-10 concentration was positively correlated with parasitaemia in $\mathrm{P}$. vivax and $\mathrm{P}$. falciparum-infected patients. The same was true for the TNF- $\alpha$ concentration in $\mathrm{P}$. falciparum-infected patients. Finally, the haematological and cytokine profiles were similar between uncomplicated $\mathrm{P}$. falciparum and $\mathrm{P}$. vivax infections.

Key words: cytokines - chemokines - platelets - P. falciparum - P. vivax

Malaria remains a major health problem worldwide, with 300-500 million cases annually and nearly one million deaths (Murray et al. 2012). Although Plasmodium falciparum malaria represents the majority of these cases and is responsible for almost all of the associated mortality, Plasmodium vivax malaria has a wider geographic distribution and is responsible for high morbidity worldwide. Despite this widespread prevalence, $P$. vivax has long been overshadowed by the burden caused by $P$. falciparum. In Brazil, P. vivax accounts for more than $70 \%$ of all malaria cases. The infections are chronic, can produce profound anaemia, can be incapacitating for days or weeks and have the added complication of recurrent clinical episodes due to the developmental reactivation of hypnozoites, the dormant liver stage form (Mendis et al. 2001, Sina 2002).

It is well documented that disease severity depends strongly on the previous immunological experience of the host (Schofield \& Mueller 2006). Therefore, in areas

doi: $10.1590 / 0074-0276140275$

Financial support: DECIT, CNPq

+ Corresponding author: 1ila@ioc.fiocruz.br

Received 24 May 2013

Accepted 6 December 2013 of high malaria transmission, infants and young children are more frequently affected, whereas in malaria-endemic areas, where transmission is unstable, adults are the most commonly affected population (Schofield \& Mueller 2006). Although sterile immunity is most likely never achieved, individuals can develop essentially complete protection from severe illness and death after continuous exposure (Langhorne et al. 2008). Clinical malaria infection causes a range of symptoms from asymptomatic infection to severe disease complication. Although different theories have been proposed to explain the disease in humans, malaria pathogenesis remains controversial (Miller et al. 2002, Weatherall et al. 2002).

Although there is an extensive body of literature describing variations in haematological parameters and immune cytokine responses during malaria infection, their link to disease manifestation is still a subject of much debate. The subject of haematological changes is controversial in the malaria field, although anaemia and thrombocytopaenia are the most prominent alterations during both $P$. falciparum and $P$. vivax infections (Agarwal et al. 1983, Lacerda et al. 2011). Severe malaria has long been associated with high circulating levels of inflammatory cytokines such as tumour necrosis factor (TNF)- $\alpha$, interleukin (IL)-1 and IL-6. Studies have demonstrated a link between TNF- $\alpha$, IL- 6 , IL-10 and the severity of the disease in human malaria (Akanmori et 
al. 2000) and high plasma levels of these cytokines are found at diagnosis, even in uncomplicated malaria cases (Baptista et al. 1997). Anti-inflammatory cytokines have also been found to have important roles in the immune response against Plasmodium. IL-10 has an important role as an immunoregulator during $P$. falciparum infection, neutralising the effects of other cytokines produced by T-helper (Th)1 and CD8 cells (Couper et al. 2008, Langhorne et al. 2008). In recent years, increasing evidence has suggested that regulatory $\mathrm{T}$ cells are key anti-inflammatory cells that are critical to limiting the inflammatory response (Hansen \& Schofield 2010). Additionally, IL-10 and granulocyte-colony stimulating factor (G-CSF) have been found to be elevated and correlated with parasitaemia in asymptomatic pregnant women in Ghana (Wilson et al. 2010), suggesting that these cytokines may act to reduce symptoms. Paradoxically, a significant number of cytokines and chemokines have been associated with severe disease, in particular IL-1ß (Brown et al. 1999), IL-2 (Ramharter et al. 2003), IL-6 (Kern et al. 1989, el-Nashar et al. 2002), interferon (IFN)- $\gamma$ (Day et al. 1999, Ramharter et al. 2003), TNF- $\alpha$ (Kern et al. 1989, Kwiatkowski et al. 1990, el-Nashar et al. 2002, Ramharter et al. 2003), IL-4 (Kumaratilake \& Ferrante 1992, Eisenhut 2010), IL-10 (Day et al. 1999, Othoro et al. 1999, Ramharter et al. 2003) and macrophage inflammatory protein (MIP)-1 $\beta$ (Ochiel et al. 2005), whereas low levels of regulatory cytokines, such as TGF- $\beta$ and IL-10, have been correlated with acute malaria (Peyron et al. 1994, Hansen \& Schofield 2010). Studies in Brazil, where malaria is predominantly hypo or mesoendemic and the incidence of complications and mortality due to malaria infections is very low, increased IFN- $\gamma$ concentrations have been reported in $P$. vivax and $P$. falciparum patients, whereas increased IL-10 levels have been observed only in P. vivax patients (Medina et al. 2011). A comparison between asymptomatic individuals with those experiencing severe malaria showed that the IFN- $\gamma / \mathrm{IL}-10$ ratio was higher in severe cases, whereas IL-10 levels were elevated in asymptomatic individuals (Andrade et al. 2010). Another study in the same area showed a significant increase in the concentrations of TNF- $\alpha$, IFN- $\gamma$, migration inhibitory factor and monocyte chemotactic protein (MCP)-1 in patients with $P$. vivax and $P$. falciparum, whereas IL-10 was observed in only $P$. vivax-infected patients (Fernandes et al. 2008).

A retrospective analysis of a databank containing clinical epidemiological data from patients with mild or severe malaria from the state of Rondônia (RO), Brazil revealed that systematic analysis of several inflammatory mediators that are measured simultaneously can characterise the overall immune response pattern of patients infected with $P$. vivax. In the group of patients with severe malaria, $P$. vivax parasitaemia had several positive interactions with inflammatory mediators such as TNF- $\alpha$, IFN- $\gamma$ and IL-10 (Mendonça et al. 2013).

Although clinical descriptions of the illness caused by $P$. vivax infection are available, data regarding inflammatory patterns are scarce and few studies have evaluated numerous different cytokines in a single patient group in paired samples using one methodology. A better approach for investigating putative relationships between cytokine production and disease state is to simultaneously profile temporal changes in multiple cytokines. Therefore, in this study, we determined the concentrations of various cytokines and chemokines directly from plasma in an endemic population infected with $P$. falciparum and $P$. vivax as part of an effort to identify a single marker or combination of cytokines and chemokines that could potentially characterise differences between the acute and convalescent phases (pre and post-treatment time points) of infection and to discriminate between $P$. falciparum and $P$. vivax infections.

\section{SUBJECTS, MATERIALS AND METHODS}

Subjects and sampling - The study was carried out in Porto Velho, RO, an unstable malaria-endemic area, where $P$. vivax accounts for more than $75 \%$ of all malaria cases (Oliveira-Ferreira et al. 2010). Symptomatic patients diagnosed with malaria infection by a thick blood smear in an outpatient clinic in Porto Velho were asked to participate in the study. A total of 71 patients were enrolled for the study, 47 and 24 of whom were infected with $P$. vivax and $P$. falciparum, respectively. Blood samples were collected by venipuncture from each patient at the day of diagnosis (D0 - in the acute phase) and, after collection, all patients were treated with the regimen recommended by the Brazilian Ministry of Health (MS 2010). Patients returned 15 days later (D15 - in the convalescent stage) for follow-up examinations and paired blood samples were collected from 40 P. vivax and 15 P. falciparum infected patients. All patients were symptomatic and had clinical symptoms ranging from very mild illness to full-blown paroxysms, but there were no severe or complicated malaria cases. The patients were positive for either $P$. falciparum or $P$. vivax parasites as determined by microscopy using thick and thin blood smears at D0. Asexual blood forms of P. falciparum or $P$. vivax were cleared from the peripheral blood of all patients included in the study following therapy and no parasite reappearance was observed during follow-up. The control group $(n=12)$ was composed of apparently healthy individuals who lived in the same area, but were negative for malaria parasites as determined thick blood smear and had not reported any malaria episodes for at least one year. Ethical approval for the study was granted by the Oswaldo Cruz Foundation Ethical Committee and by the National Ethical Committee of Brazil and informed consent was given by the patients.

Laboratory tests - Thick and thin blood films were stained with Giemsa and the Plasmodium species were identified and parasitaemia was determined by microscopic examination at D0 and D15. Parasitaemia levels were estimated by counting the number of parasites (all species and stages) per 200 white blood cells (WBC) on blood films. If fewer than nine parasites were detected, 300 additional leucocytes were counted to obtain more precise results. Complete blood cell counts, including haematologic indices, were performed at D0 and D15 using an automatic haematology analyser (Pentra ABX) and peripheral blood smears were performed for routine dif- 
ferential blood cellular quantification. The cell counters provided data on WBC counts and red blood cell (RBC) counts, haemoglobin $(\mathrm{Hb})$ levels, haematocrit and reticulocyte, platelet, lymphocyte, eosinophil, segmented neutrophil, band cell, monocyte and basophil counts. The smears were examined by qualified pathologists. The presence of reticulocytes was evaluated using Brilliant Cresyl blue solution. The patients were considered anaemic when their $\mathrm{Hb}$ levels were $\leq 13 \mathrm{~g} / \mathrm{dL}$ blood in males and $\leq 12 \mathrm{~g} / \mathrm{dL}$ of blood in females. Thrombocytopaenia was defined as a platelet count $<150 \times 10^{6} / \mathrm{mL}$.

Multiplex microsphere cytokine immunoassay - The levels of 16 cytokines and chemokines were detected in plasma samples using Luminex technology (Luminex Corporation, Austin, TX, USA). Thirteen cytokines [IL-1 $\beta$, IL-2, IL-4, IL-5, IL-6, IL7, IL-10, IL-12 p70, IL-17, IFN- $\gamma$, TNF- $\alpha$, G-CSF, granulocyte-macrophage colony-stimulating factor (GM-CSF)] and three chemokines (IL-8, MCP-1 and MIP-1 $\beta$ ) were analysed using a BioPlex-Kit assay (Bio-Rad Laboratories, Hercules, CA, USA). The assay was performed according to the manufacturer's instructions using a BioPlex-kit in combination with the Luminex system. Briefly, $50 \mu \mathrm{L}$ of standard or test sample along with $50 \mu \mathrm{L}$ of mixed beads were added into the wells of a pre-wetted 96-well microtitre plate. After $1 \mathrm{~h}$ of incubation and washing, $25 \mu \mathrm{L}$ of detection antibody mixture was added and the samples were incubated for $30^{\circ} \mathrm{C}$ min and then washed. Finally, $50 \mu \mathrm{L}$ of streptavidin-PE was added and after $10^{\circ} \mathrm{C}$ min of incubation and washing, the beads were resuspended in $125 \mu \mathrm{L}$ assay buffer and analysed using a BioPlex suspension array system (Bio-Rad Laboratories) and the Bio-Plex manager software (v.3.0). A minimum of 100 beads per region were analysed. A curve fit was applied to each standard curve according to the manufacturer's manual and sample concentrations were interpolated from the standard curves. The limit of cytokine detection using this method was $2 \mathrm{pg} / \mathrm{mL}$ for all cytokines and chemokines. The median cytokine and chemokine levels in 12 healthy controls were $2 \mathrm{pg} / \mathrm{mL}$ for IL-1 IL-2, IL-4, IL-5, IL-6, IL-7, IL-10, IL-12 p70, IL-10 and GM-CSF, $15.53 \mathrm{pg} / \mathrm{mL}$ for IFN- $\gamma, 12.58 \mathrm{~mL}$ for TNF- $\alpha$, $4.3 \mathrm{pg} / \mathrm{mL}$ for GCS-F, $495 \mathrm{pg} / \mathrm{mL}$ for MCP-1 and 594.5 $\mathrm{pg} / \mathrm{mL}$ for MIP-1 $1 \beta$.

Statistical analysis - Survey data were recorded and entered into a database created with Epi Info 2007 (Centers for Disease Control and Prevention, Atlanta, GA, USA). Analyses were performed using Predictive Analytics Software v.17.0 (SPSS Inc, Chicago, IL, USA) and Prism v.5 (GraphPad Software Inc, San Diego, CA, USA). Differences in median haematological parameters and cytokine levels were expressed as medians and interquartile ranges (IR) and compared using Bonferroni's multiple comparison test. When this test indicated a significant difference $(\mathrm{p}<0.05)$ among pairwise groups, a Mann-Whitney $U$ test was used. To evaluate the significant differences in haematological and cytokine parameters between the acute and convalescent phases from the same patient, non-parametric paired $t$ tests were used. Differences in proportions were evaluated using the chi-squared test. Finally, the correlations between parasitaemia, blood cells and cytokine levels were calculated using Spearman's rank correlation coefficient and $\mathrm{p}<0.05$ were considered statistically significant.

\section{RESULTS}

Study subjects - Seventy-one patients infected with malaria were enrolled in the study. The majority of the patients were male. There were no differences in mean age, time of residence in the endemic area and number of past malaria episodes between P. vivax $(\mathrm{n}=47)$ and P. falciparum $(\mathrm{n}=24)$ infected patients. All patients presented general clinical symptoms such as history of fever and headache at the time of enrolment independent of Plasmodium species. The time elapsed between the appearance of the first symptoms and malaria diagnosis was similar between patients with $P$. vivax (3 days) and $P$. falciparum (3.5 days). Although the mean parasitaemia was higher in P. falciparum-infected individuals than $P$. vivax-infected individuals, this difference was not statistically significant. All patients were parasitaemia-negative by day 15 of follow up after receiving effective drug treatment. The characteristics of the participants are presented in Table I.

Haematological results - To investigate haematological changes during malaria infection, differential haematological parameters during the acute and convalescent phases, expressed as the median (IR), are shown in Table II. The median lymphocyte and platelet counts in $P$. falciparum and $P$. vivax patients during acute disease were lower than in the control subjects and returned to control reference levels during the convalescent stage. In contrast, the median band cell counts were elevated in both $P$. vivax and $P$. falciparum-infected patients during the acute phase $(\mathrm{p}=0.0041$ and $\mathrm{p}=0.0001$, respectively $)$ and returned to normal levels during the convalescent stage. We also found that patients with acute $P$. vivax infection had low eosinophil counts $(\mathrm{p}=0.013$, control values $153 / \mu \mathrm{L}$ ) that increased during the convalescent stage. All other haematological values were similar among $P$. falciparum-infected, P. vivax-infected and control subjects. Although no differences in $\mathrm{Hb}$ levels were observed between $P$. vivax and $P$. falciparum patients during the acute phase, anaemia was detected in $29.2 \%$ of $P$. falciparum and in $55.3 \%$ of $P$. vivax patients. However, these frequencies were not significantly different from those of control subjects, $38.9 \%$ and they remained similar during the convalescent phase, during which $60 \%$ of patients previously infected by $P$. vivax and $40 \%$ previously infected by $P$. falciparum were anaemic.

Circulating cytokine and chemokine levels during the acute and convalescent phases of a malaria episode - The data in Fig. 1 compare circulating cytokine and chemokine levels in patients infected with $P$. vivax and $P$. falciparum. First, the cytokines IL-5, IL-7 and GM-CSF were not detectable in most plasma samples and no differences were observed in MCP-1 levels compared with controls. During the acute phase, P. vivax and $P$. falciparum patients had significantly higher IL-6, IL-8, IL-17, IFN- $\gamma$, TNF- $\alpha$, MIP-1 $\beta$ and G-CSF plasma 
TABLE I

Epidemiological and parasitological data of Plasmodium vivax and Plasmodium falciparum infected-patients

\begin{tabular}{|c|c|c|}
\hline & $\begin{array}{l}\text { P. vivax } \\
(\mathrm{n}=47)\end{array}$ & $\begin{array}{l}\text { P. falciparum } \\
(\mathrm{n}=24)\end{array}$ \\
\hline Male $[\mathrm{n}(\%)]$ & $35(74.5)$ & $19(79.2)$ \\
\hline Age [n (\%)] & $28(22-38)$ & $28.5(23-41)$ \\
\hline $\begin{array}{l}\text { Years of residence in } \\
\text { malaria endemic area }[\mathrm{n}(\%)]\end{array}$ & $24(21-36)$ & $27(19-38)$ \\
\hline $\begin{array}{l}\text { Years of residence in } \\
\text { the state of Rondônia }[n(\%)]\end{array}$ & $23(16-28)$ & $23(16-28)$ \\
\hline $\begin{array}{l}\text { Total number of past } \\
\text { malaria episodes [n (\%)] }\end{array}$ & $3(1-8)$ & $3.5(1-10)$ \\
\hline $\begin{array}{l}\text { Months since last } \\
\text { malaria episodes }[\mathrm{n}(\%)]\end{array}$ & $10(2.2-24)$ & $12.5(2-102)$ \\
\hline $\begin{array}{l}\text { Parasitaemia } \\
\text { (number of parasites } / \mu \mathrm{L} \text { ) }\end{array}$ & $2,293(874-17,933)$ & $1,328(793-12,623)$ \\
\hline $\begin{array}{l}\text { Days since the } \\
\text { symptoms began }[\mathrm{n}(\%)]\end{array}$ & $3(1-8)$ & $3.5(1.5-10)$ \\
\hline \multicolumn{3}{|l|}{ Symptoms [n (\%)] } \\
\hline Fever & $39 / 83$ & $22 / 92$ \\
\hline Chills & $32 / 68$ & $20 / 83$ \\
\hline Headache & $39 / 83$ & $21 / 87$ \\
\hline Vomiting & $23 / 49$ & $20 / 83$ \\
\hline Myalgia & $31 / 66$ & $21 / 87$ \\
\hline
\end{tabular}

the values on Table indicate median (interquartile range). Frequency of symptoms and gender were compared between $P$. vivax and $P$. falciparum infected-patients by chi-squared test. Mann-Whitney $U$ test were used to compare parasitaemia, days since the symptoms began, time since the last malaria infection, number of previously malaria episodes and time in malaria endemic area. There were not statistical differences on epidemiological, clinical and parasitological data between patients infected by $P$. falciparum and $P$. vivax.

concentrations than controls. To investigate changes in cytokine levels during infection, we compared cytokine levels in the sera from the same patient during the acute and convalescent phases and plasma levels of IL-6, IL-8, IL-17, IFN- $\gamma$, TNF- $\alpha$ MIP-1 $\beta$ and G-CSF were higher during the convalescent phase. Although P. falciparum and $P$. vivax malaria patients have similar cytokine profiles during infection, $P$. falciparum patients presented higher levels of IL-6, IL-8, IL-17, IFN- $\alpha$, MIP-1 $\beta$ and GCSF than $P$. vivax patients during the convalescent phase. In contrast, only $P$. vivax patients presented higher levels of TNF- $\alpha$ during the convalescent phase than during the acute phase of infection. IL-10 levels were detected at high concentrations in the majority of $P$. falciparum and $P$. vivax patients during the acute phase and returned to completely normal levels during the convalescent phase. The median IL-10 concentration during the acute phase was $1,175 \mathrm{pg} / \mathrm{mL}(\mathrm{IR}=155-3,135)$ at D0 and $2 \mathrm{pg} / \mathrm{mL}$ $(\mathrm{IR}=2-2)$ at D15 and $1,187 \mathrm{pg} / \mathrm{mL}(\mathrm{IR}=502.5-3049)$ at $\mathrm{D} 0$ and $2 \mathrm{pg} / \mathrm{mL}(\mathrm{IR}=2-149.8)$ at D15 in $P$. vivax and $P$. falciparum-infected patients, respectively.

The levels of IL-1 $\beta$, IL-4 and IL-12 were similar to those of the controls during the acute phase for both $P$. falciparum and $P$. vivax patients and were higher during the convalescent phase, with the exception of IL-12, which was higher only in the $P$. falciparum group. The plasma
IL-2 concentration was determined only during the acute phase in P. falciparum patients. Although the median IL-2 levels were higher during the convalescent phase, these differences were not statistically significant.

Relationship between parasitaemia and other variables - Spearman's correlation coefficient values and $p$ values are shown in Fig. 2. Various combinations of variables were analysed for possible correlational relationships. In $P$. vivax patients, we found a statistically significant negative correlation between platelet count and parasitaemia during the acute phase (Fig. 2A). The acute phase plasma IL-10 concentration was positively correlated with parasitaemia in P. vivax (Fig. 2C) and $P$. falciparum-infected patients (Fig. 2D). The same was true for the TNF- $\alpha$ concentration in P. falciparum-infected patients (Fig. 2B). No relationship was found between parasitaemia and the other blood cell counts or the concentration of others cytokines assayed (data not shown).

\section{DISCUSSION}

Haematological changes, such as alterations in total and differential WBC counts, are widely used to differentiate between several types of infections and to monitor the course of diseases (Ventura et al. 1999, Lathia \& Joshi 2004, Tangpukdee et al. 2008). Malaria-induced changes in the differential white cell counts are very diverse and 
TABLE II

Comparison of haematological profiles of control group and patients infected by Plasmodium vivax and Plasmodium falciparum on acute and convalescent phase of infection

\begin{tabular}{lccccc}
\hline & \multicolumn{2}{c}{ P. vivax } & \multicolumn{2}{c}{ P. falciparum } \\
\cline { 2 - 5 } & $\begin{array}{c}\text { Acute phase } \\
(\mathrm{n}=47)\end{array}$ & $\begin{array}{c}\text { Convalescent phase } \\
(\mathrm{n}=40)\end{array}$ & $\begin{array}{c}\text { Acute phase } \\
(\mathrm{n}=24)\end{array}$ & $\begin{array}{c}\text { Convalescent phase } \\
(\mathrm{n}=15)\end{array}$ & $\begin{array}{c}\text { Control } \\
(\mathrm{n}=12)\end{array}$ \\
\hline Erythrogram & & & & \\
RBC (x10 $/ \mu \mathrm{L})$ & $4.6(4.3-5.1)$ & $4.3(4-4.7)$ & $4.9(4.5-5.4)$ & $4.9(4.7-5.3)$ & $4.6(4.2-5)$ \\
Haematocrit $(\%)$ & $41(38-45)$ & $39(35.5-42)$ & $44(39-45)$ & $39(38-43)$ & $39(38-43)$ \\
Haemoglobin $(\mathrm{g} / \mathrm{dL})$ & $14(12.5-15.5)$ & $12.6(11.7-13.9)$ & $14.5(13.9-15.2)$ & $13.8(11.9-14)$ & $13.8(13-15)$ \\
Reticulocyte $(\%)$ & $0.5(0.3-0.8)$ & $0.3(0.25-0.5)$ & $0.35(0.27-0.45)$ & $0.4(0.3-0.55)$ & $0.35(0.25-0.50)$ \\
Platelet $\left(\mathrm{x} 10^{3} / \mu \mathrm{L}\right)$ & $156(105-182)^{a, b}$ & $277(234.5-342.5)$ & $135(96.25-135)^{a, b}$ & $261(195-365)$ & $275(231-315)$ \\
Leucogram $(/ \mu \mathrm{L})$ & & & & \\
WBC & $5,100(4,000-6,600)$ & $5,550(5,125-7,000)$ & $4,650(3,825-6,375)$ & $5,900(5,000-7,300)$ & $6,400(5,650-7,550)$ \\
Lymphocyte & $1,020(780-1,406)^{a, b}$ & $2,062(1,625-2,389)$ & $1,038(571.5-1,536)^{a, b}$ & $2,000(1,770-2,920)$ & $2,250(1,872-2,570)$ \\
Basophil & $0(0-0)$ & $0(0-0)$ & $0(0-0)$ & $0(0-0)$ & $0(0-0)$ \\
Eosinophil & $67(33-168)^{b, c}$ & $288.5(162.8-418.5)$ & $82(34-255)$ & $288(108-629)$ & $153(82.5-265.5)$ \\
Band cell & $63(0-282)^{d}$ & $0(0-0)$ & $118(36-369.5)^{d}$ & $0(0-0)$ & $0(0-0)$ \\
Neutrophil & $3,468(2,240-4,480)$ & $3,048(2,377-3,558)$ & $3,432(2,060-4,212)$ & $2,911(2,031-3,650)$ & $3,830(3,075-4,654)$ \\
Monocyte & $360(214.5-470.5)$ & $360(214.5-470.5)$ & $350.5(215-527.3)$ & $292(216-426)$ & $351.5(250.5-547.5)$ \\
\hline
\end{tabular}

$a: \mathrm{p}<0.001$ between indicated infected group and control; $b: \mathrm{p}<0.0001$ between acute and convalescent phase of indicated group; $c: \mathrm{p}<0.05$ between indicated infected group and control; $d: \mathrm{p}<0.01$ between indicated infected group and control. The values indicate median (interquartile range). Comparison between control group and patients infected by $P$. vivax and infected by $P$. falciparum were evaluated by Bonferroni's multiple comparison test. When the test indicated a significant difference $(\mathrm{p}<$ 0.05 ) between groups pairwise, Mann-Whitney $U$ test were used. To assess the significant differences in haematological parameters between acute and convalescent phase from the same patient, non parametric paired $t$ tests were used. No statistical differences were observed between $P$. vivax and $P$. falciparum-infected patients on acute or convalescent phase. Acute phase: day of diagnosis; convalescent phase: 15 days after diagnosis; RBC: red blood cell; WBC: white blood cell.

contradictory and include leucopoenia, lymphopaenia, lymphocytosis, the presence of atypical lymphocytes, monocytosis, neutropaenia, neutrophilia, immature neutrophils (band cells), eosinopaenia, eosinophilia and leukemoid reactions (Wickramasinghe \& Abdalla 2000, Price et al. 2001, Taylor et al. 2008, Gonzalez et al. 2009). The findings of our study show that increased band cells and low lymphocyte and eosinophil counts are common during acute $P$. falciparum and $P$. vivax malaria. The decreased lymphocyte levels during malaria infection have been attributed to the reallocation of cells to deep lymphoid organs or by parasite induced apoptosis of human mononuclear cells (Hviid et al. 1997, Balde et al. 2000). Both phenomena most likely contributed to the lymphopaenic state in our patients. Fifteen days following treatment, when no parasites were detected in either $P$. falciparum and $P$. vivax patients, the lymphocyte counts were similar to those in the control subjects, indicating that this period of time was sufficient for the patients to achieve lymphocyte homeostasis. With respect to eosinopaenia during the acute phase, it has been suggested that malaria either suppresses eosinophil production and release from the bone marrow or enhances the peripheral removal of these cells (Davis et al. 1991, Aubouy et al. 2002, Tangpukdee et al. 2008). The increased eosinophil counts we observed post-treatment have been observed in previous studies (Kurtzhals et al. 1998, Tangpukdee et al. 2008). In those studies, the induction of eosinophils was attributed to various factors such as higher release of eosinophils after temporary bone marrow suppression caused by Plasmodium, a direct response to the parasite or a response to antimalarial drugs.

The transitory increase in band cells that was observed in both infections indicates a stronger stimulus for neutrophil production during the acute phase. In this case, early or premature release of neutrophils from the bone marrow occurs, resulting in an increased proportion of younger, less well-differentiated neutrophils into the circulation. Though this alteration is common knowledge in other acute diseases, very few studies evaluating these disturbances have been conducted for this cell type in malaria patients (Hanscheid et al. 2008, Lima-Junior et al. 2012).

Erythrogram abnormalities are also very common in malaria patients and the most prominent alterations are anaemia and thrombocytopaenia (Collins et al. 2003, Ghosh 2007, Araujo et al. 2008, Fernandes et al. 2008, Leowattana et al. 2010, Lacerda et al. 2011). In our study, the absence of marked anaemia in malaria patients may be due to the early diagnosis and prompt treatment, free of charge, provided by the malaria control program in Brazil. However, low platelet counts were observed during acute infection. Although some authors have de- 

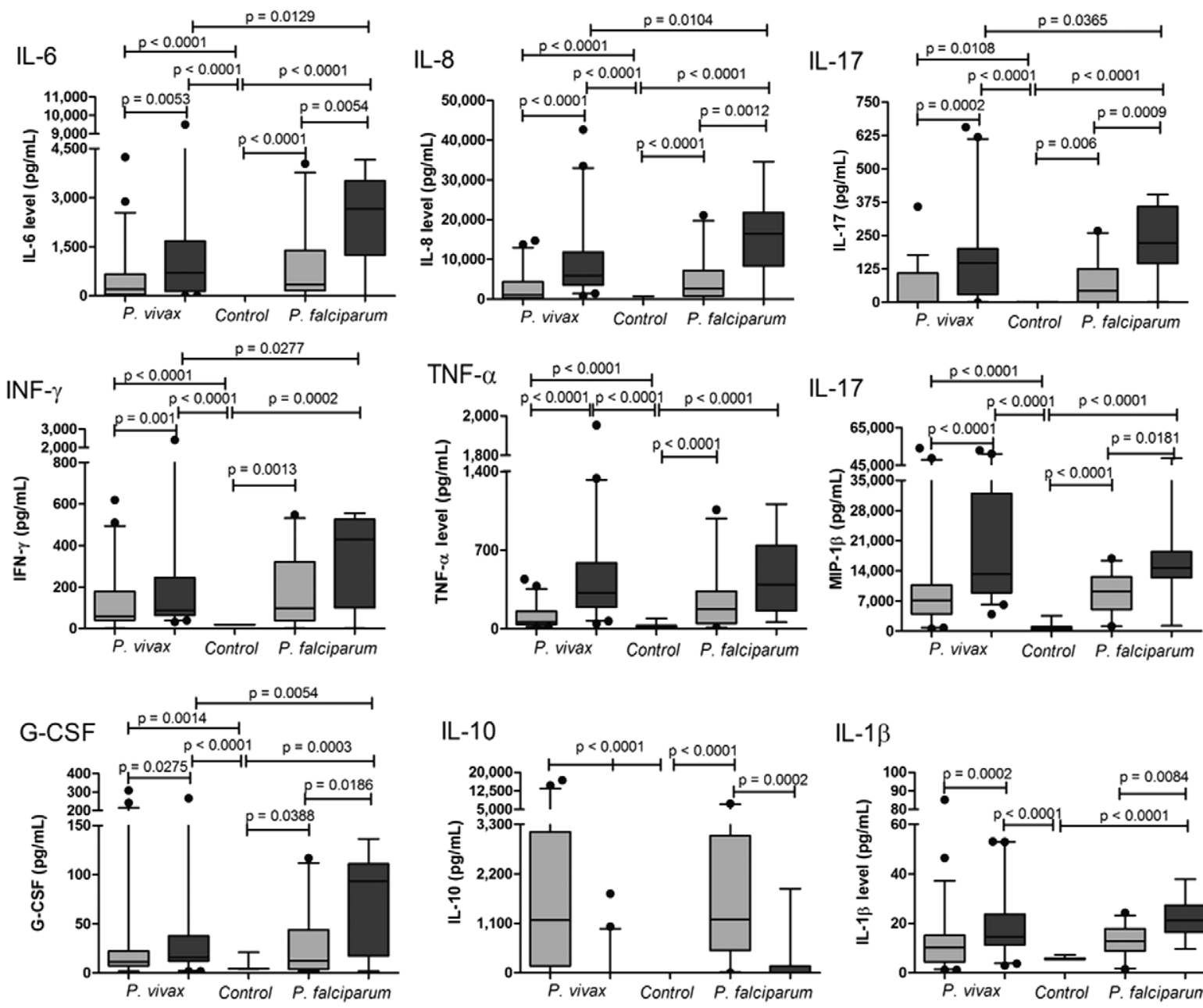

IL-1 $\beta$

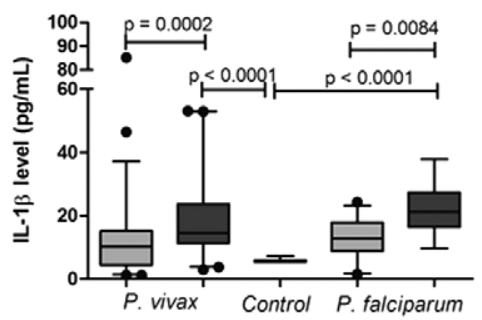

IL-4
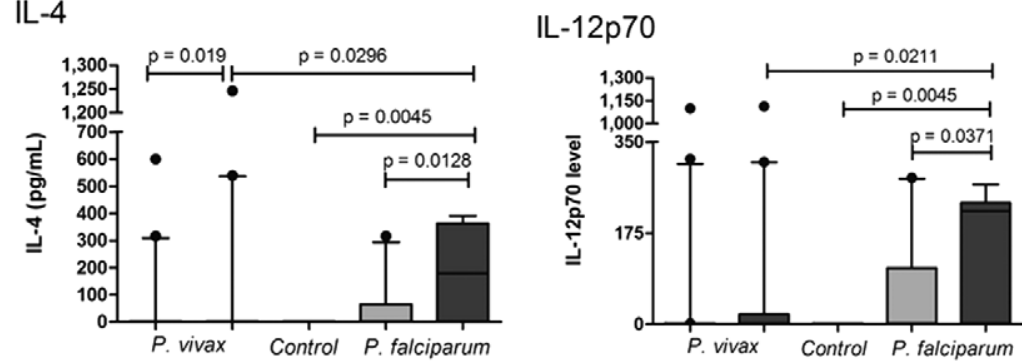

Fig. 1: comparison of serum cytokines and chemokines levels between control, Plasmodium vivax and Plasmodium falciparum patients in acute and convalescent phase of infection. The control group was indicated by white bars, while acute and convalescent phase of infection were indicated by light and dark gray bars, respectively. The boxes represent the values between $25-75 \%$ quartile and the line indicates the median. The whiskers indicate the $5 \%$ and $95 \%$ percentiles. Comparison between control group and patients infected by $P$. vivax and infected by P. falciparum were evaluated by compared by Bonferroni's multiple comparison test. When the test indicated a significant difference $(\mathrm{p}<0.05)$ between groups pairwise, Mann-Whitney $U$ test were used. To assess the significant differences between acute and convalescent phase in $P$. vivax and $P$. falciparum infected-patients non parametric paired $t$ tests were used. The significant differences and the respective $\mathrm{p}$ values were indicated on figure. G-CSF: granulocyte-colony stimulating factor; IFN: interferon; IL: interleukin; MIP: macrophage inflammatory protein; TNF: tumour necrosis factor.

scribed more intense thrombocytopaenia during acute falciparum malaria compared to vivax malaria whereas others have described the opposite, no difference in thrombocytopaenia was observed between these types of malaria in our study (Ghosh 2007, Taylor et al. 2008). However, we did observe a negative correlation between platelet counts and parasitaemia during acute $P$. vivax infection only. These inconsistent relationships may reflect differences in epidemiology, the immune status of malaria patients and many others factors (Casals-Pascual et al. 2006). Several causes of thrombocytopaenia have been suggested. Disseminated intravascular coagula- 
A

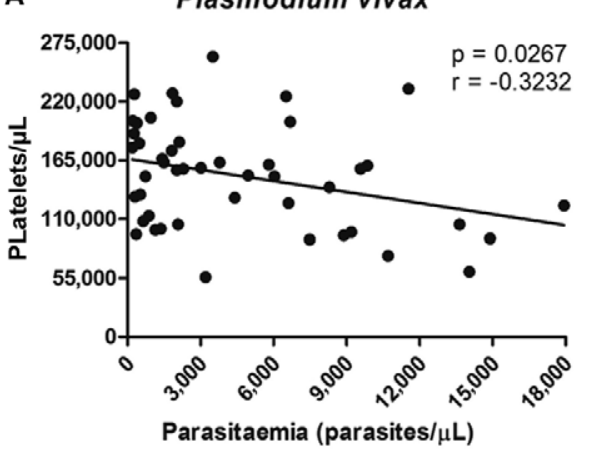

C

Plasmodium vivax

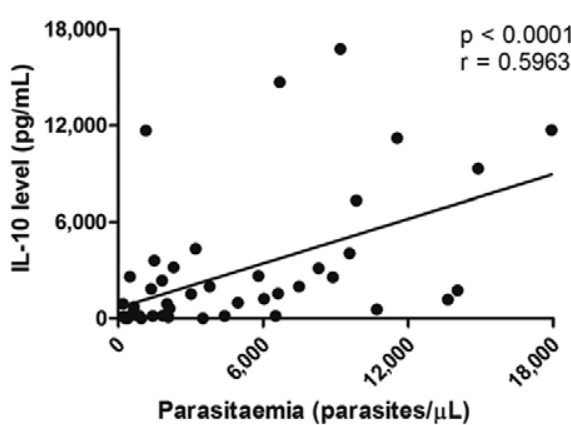

B

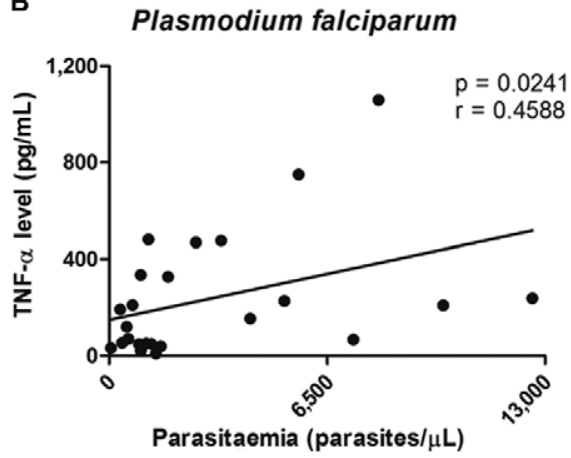

D

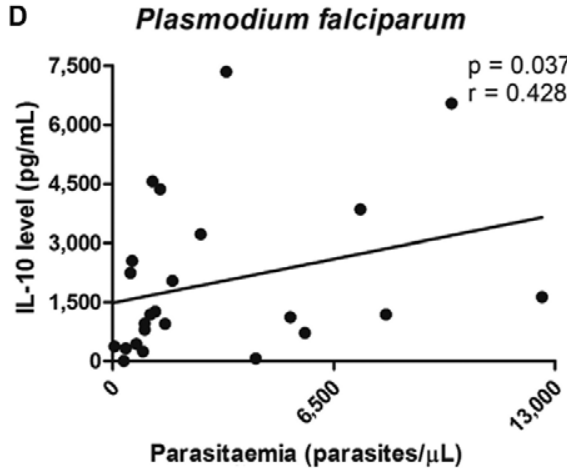

Fig. 2: relationship between parasitaemia and other variables. Associations between parasitaemia, blood cells and cytokines level were investigated by Spearman's rank correlation coefficient and p values $<0.05$ were considered statistically significant. IL: interleukin; TNF: tumour necrosis factor.

tion, immune mechanisms, dysmyelopoiesis and hypersplenism are some examples of mechanisms that could be related to platelet reduction in malaria patients (Patel et al. 2004, Wassmer et al. 2008, Bueno et al. 2011).

The role of cytokine signalling during malaria episodes is still far from being understood. The most famous inflammatory marker of severe malaria is TNF- $\alpha$, which is closely associated with fever, paroxysms, anaemia, cerebral malaria and many other systemic infection symptoms (Karunaweera et al. 2003, Armah et al. 2005). In our study, the cytokine and chemokine profiles in acute $P$. vivax and $P$. falciparum patients were similar. The acute phase was characterised by the presence of proinflammatory cytokines (IL-1 $\beta$, IL-2, IL-6, IL-17, IFN- $\gamma$, TNF- $\alpha$ ), anti-inflammatory cytokines (IL-4 and IL-10), chemokines (IL-8, MIP-1) and G-CSF in most malaria patients. During the convalescent phase (D15), the levels of all these cytokines increased compared with D0, except for IL-10 levels, which were elevated only during the acute phase and were associated with parasite density. We and others have shown a marked IL-10 response during symptomatic uncomplicated $P$. vivax malaria infection and a significant positive correlation between plasma IL-10 levels and parasite density during $P$. vivax and $P$. falciparum infection. The discordant results regarding cytokine production during the convalescent phase in our study suggests different regulatory mechanisms for early parasite clearance. Whether the differences in serum cytokine levels noted in our study are biologically significant is also unclear. It is tempting to speculate that the phagocytic cells are committed to a more Th1-biased phenotype during drug-induced clearance of parasitaemia and release of parasite metabolites, such as haemozoin, which is a known inducer of pro-inflammatory responses via signalling through Toll-like receptors 9 (Coban et al. 2005). Nonetheless, before the initiation of antimalarial treatment, a notably high IL-10 concentration that markedly decreased with the resolution of parasitaemia was observed and this down regulation of the Th2 response discriminated the successfully treated malaria patients. IL-10 has a number of effects and IL-10 inhibited IL-6, IFN- $\gamma$ and TNF- $\alpha$ secretion and function in an in vitro malaria model when anti-IL-10 antibody was produced. Another plausible cause for the increase in several cytokine levels between the acute and convalescent phases could be the diminished suppressive effect by IL-10 on other cytokines such as pro-inflammatory cytokines, as well as a reduced systemic inflammatory response due to all haematological alterations returning to references values. IL-10 perturbations appear to have the most significant inhibitory effect on other cytokine concentrations. In this endemic area, we were unable to rule out concomitant intestinal parasite infections with organisms such as helminths, which potentially influenced the results (Hartgers \& Yazdanbakhsh 2006). An association of IL-10 levels with parasitaemia has also been reported in Plasmodium knowlesi and $P$. vivax infections. Moreover, IL-10 levels in both $P$. vivax and $P$. knowlesi patients were elevated, but were not associated with markers of disease severity (Cox-Singh et al. 2011). In contrast, the IFN $\gamma / \mathrm{IL}-10$ ratio has been suc- 
cessfully used as a marker for pathological inflammatory activity in $P$. vivax patients with varying disease severity (Andrade et al. 2010). Several studies report that IL-10 has been implicated in malaria pathophysiology (Dodoo et al. 2002, Corrigan \& Rowe 2010, Cox-Singh et al. 2011). In our study, IL-10 predominated in the early anti-inflammatory response in P. falciparum and $P$. vivax-infected patients and dropped drastically during the convalescent phase when malaria had been cured in all patients. In conclusion, a complex array of cytokines is released in adult patients with uncomplicated malaria infection with apparent feedback inhibition and cross-regulatory functions. IL-10 appears to be involved during the acute phase of the disease and its decrease correlates with recovery as biological and clinical malaria features disappear. Further studies are required to determine whether these elevated IL-10 levels play a beneficial role by reducing the parasite-induced inflammatory response.

Additionally, there are no reports of cytokine concentrations in humans 15 days after the beginning of treatment; therefore, the data presented here could for the first time indicate a shift from a Th1/Th2 balanced response to a more pronounced Th1-regulated immune response during the first 15 days of uncomplicated malaria treatment in Brazilian endemic areas. Differences in epidemiology, nutritional status, demographic factors and the presence of co-infections are factors that could be related to the ambiguous findings of previous studies.

\section{ACKNOWLEDGEMENTS}

To the Secretary of Health of RO and LACEN/RO, for the infrastructure support, and to all individuals who participated in this study, for their cooperation and donation of blood.

\section{REFERENCES}

Agarwal SS, Nath A, Sharma P, Srivastava IK, Dwivedi SR, Dutta GP 1983. Comparative evaluation of Plasmodium knowlesi and $P$. cynomolgi antigens in the indirect fluorescent antibody test for human malaria. Indian J Med Res 77: 616-622.

Akanmori BD, Kurtzhals JA, Goka BQ, Adabayeri V, Ofori MF, Nkrumah FK, Behr C, Hviid L 2000. Distinct patterns of cytokine regulation in discrete clinical forms of Plasmodium falciparum malaria. Eur Cytokine Netw 11: 113-118.

Andrade BB, Reis-Filho A, Souza-Neto SM, Clarencio J, Camargo LM, Barral A, Barral-Netto M 2010. Severe Plasmodium vivax malaria exhibits marked inflammatory imbalance. Malar J 9: 13.

Araujo CF, Lacerda MVG, Abdalla DSP, Lima ES 2008. The role of platelet and plasma markers of antioxidant status and oxidative stress in thrombocytopenia among patients with vivax malaria. Mem Inst Oswaldo Cruz 103: 517-521.

Armah H, Wired EK, Dodoo AK, Adjei AA, Tettey Y, Gyasi R 2005. Cytokines and adhesion molecules expression in the brain in human cerebral malaria. Int J Environ Res Public Health 2: 123-131.

Aubouy A, Deloron P, Migot-Nabias F 2002. Plasma and in vitro levels of cytokines during and after a Plasmodium falciparum malaria attack in Gabon. Acta Trop 83: 195-203.

Balde AT, Aribot G, Tall A, Spiegel A, Roussilhon C 2000. Apoptosis modulation in mononuclear cells recovered from individuals exposed to Plasmodium falciparum infection. Parasite Immunol 22: 307-318.

Baptista JL, Vanham G, Wery M, van Marck E 1997. Cytokine levels during mild and cerebral falciparum malaria in children living in a mesoendemic area. Trop Med Int Health 2: 673-679.
Brown H, Turner G, Rogerson S, Tembo M, Mwenechanya J, Molyneux M, Taylor T 1999. Cytokine expression in the brain in human cerebral malaria. J Infect Dis 180: 1742-1746.

Bueno LL, Lobo FP, Morais CG, Mourão LC, de Avila RA, Soares IS, Fontes CJ, Lacerda MV, Olortegui CC, Bartholomeu DC, Fujiwara RT, Braga EM 2011. Identification of a highly antigenic linear B cell epitope within Plasmodium vivax apical membrane antigen 1 (AMA-1). PLoS ONE 6: e21289.

Casals-Pascual C, Kai O, Newton CR, Peshu N, Roberts DJ 2006. Thrombocytopenia in falciparum malaria is associated with high concentrations of IL-10. Am J Trop Med Hyg 75: 434-436.

Coban C, Ishii KJ, Kawai T, Hemmi H, Sato S, Uematsu S, Yamamoto M, Takeuchi O, Itagaki S, Kumar N, Horii T, Akira S 2005. Tolllike receptor 9 mediates innate immune activation by the malaria pigment hemozoin. $J$ Exp Med 201: 19-25.

Collins WE, Jeffery GM, Roberts JM 2003. A retrospective examination of anemia during infection of humans with Plasmodium vivax. Am J Trop Med Hyg 68: 410-412.

Corrigan RA, Rowe JA 2010. Strain variation in early innate cytokine induction by Plasmodium falciparum. Parasite Immunol 32: 512-527.

Couper KN, Blount DG, Riley EM 2008. IL-10: the master regulator of immunity to infection. J Immunol 180: 5771-5777.

Cox-Singh J, Singh B, Daneshvar C, Planche T, Parker-Williams J, Krishna S 2011. Anti-inflammatory cytokines predominate in acute human Plasmodium knowlesi infections. PLOS ONE 6: e20541.

Davis TM, Ho M, Supanaranond W, Looareesuwan S, Pukrittayakamee S, White NJ 1991. Changes in the peripheral blood eosinophil count in falciparum malaria. Acta Trop 48: 243-246.

Day NP, Hien TT, Schollaardt T, Loc PP, Chuong LV, Chau TT, Mai NT, Phu NH, Sinh DX, White NJ, Ho M 1999. The prognostic and pathophysiologic role of pro and antiinflammatory cytokines in severe malaria. J Infect Dis 180: 1288-1297.

Dodoo D, Omer FM, Todd J, Akanmori BD, Koram KA, Riley EM 2002. Absolute levels and ratios of proinflammatory and anti-inflammatory cytokine production in vitro predict clinical immunity to Plasmodium falciparum malaria. J Infect Dis 185: 971-979.

Eisenhut M 2010. The role of interleukin-4 in the immune response to Plasmodium falciparum. Parasite Immunol 32: 470-471.

el-Nashar TM, el-Kholy HM, el-Shiety AG, Al-Zahaby AA 2002. Correlation of plasma levels of tumor necrosis factor, interleukin-6 and nitric oxide with the severity of human malaria. J Egypt Soc Parasitol 32: 525-535.

Fernandes AA, Carvalho LJ, Zanini GM, Ventura AM, Souza JM, Cotias PM, Silva-Filho IL, Daniel-Ribeiro CT 2008. Similar cytokine responses and degrees of anemia in patients with Plasmodium falciparum and Plasmodium vivax infections in the Brazilian Amazon region. Clin Vaccine Immunol 15: 650-658.

Ghosh K 2007. Pathogenesis of anemia in malaria: a concise review. Parasitol Res 101: 1463-1469.

Gonzalez B, Rodulfo H, de Donato M, Berrizbeitia M, Gomez C, Gonzalez L 2009. Hematologic variations in patient with malaria caused by Plasmodium vivax before, during and after treatment. Invest Clin 50: 187-201.

Hanscheid T, Langin M, Lell B, Potschke M, Oyakhirome S, Kremsner PG, Grobusch MP 2008. Full blood count and haemozoincontaining leukocytes in children with malaria: diagnostic value and association with disease severity. Malar J 7: 109.

Hansen DS, Schofield L 2010. Natural regulatory T cells in malaria: host or parasite allies? PLoS Pathog 6: e1000771. 
Hartgers FC, Yazdanbakhsh M 2006. Co-infection of helminths and malaria: modulation of the immune responses to malaria. Parasite Immunol 28: 497-506.

Hviid L, Kurtzhals JA, Goka BQ, Oliver-Commey JO, Nkrumah FK, Theander TG 1997. Rapid reemergence of T cells into peripheral circulation following treatment of severe and uncomplicated Plasmodium falciparum malaria. Infect Immun 65: 4090-4093.

Karunaweera ND, Wijesekera SK, Wanasekera D, Mendis KN, Carter R 2003. The paroxysm of Plasmodium vivax malaria. Trends Parasitol 19: 188-193.

Kern P, Hemmer CJ, van Damme J, Gruss HJ, Dietrich M 1989. Elevated tumor necrosis factor alpha and interleukin-6 serum levels as markers for complicated Plasmodium falciparum malaria. Am J Med 87: 139-143.

Kumaratilake LM, Ferrante A 1992. IL-4 inhibits macrophage-mediated killing of Plasmodium falciparum in vitro. A possible parasite-immune evasion mechanism. J Immunol 149: 194-199.

Kurtzhals JA, Reimert CM, Tette E, Dunyo SK, Koram KA, Akanmori BD, Nkrumah FK, Hviid L 1998. Increased eosinophil activity in acute Plasmodium falciparum infection - association with cerebral malaria. Clin Exp Immunol 112: 303-307.

Kwiatkowski D, Hill AV, Sambou I, Twumasi P, Castracane J, Manogue KR, Cerami A, Brewster DR, Greenwood BM 1990. TNF concentration in fatal cerebral, non-fatal cerebral and uncomplicated Plasmodium falciparum malaria. Lancet 336: 1201-1204.

Lacerda MVG, Mourão MPG, Coelho HCC, Santos JB 2011. Thrombocytopenia in malaria: who cares? Mem Inst Oswaldo Cruz 106 (Suppl. I): 52-63.

Langhorne J, Ndungu FM, Sponaas AM, Marsh K 2008. Immunity to malaria: more questions than answers. Nat Immunol 9: 725-732.

Lathia TB, Joshi R 2004. Can hematological parameters discriminate malaria from nonmalarious acute febrile illness in the tropics? Indian J Med Sci 58: 239-244.

Leowattana W, Tangpukdee N, Thar SK, Nakasiri S, Srivilairit S, Kano S, Wilairatana P, Krudsood S 2010. Changes in platelet count in uncomplicated and severe falciparum malaria. Southeast Asian J Trop Med Public Health 41: 1035-1041.

Lima-Junior JC, Rodrigues-da-Silva RN, Pereira VA, Storer FL, Perceda-Silva DS, Fabrino DL, Santos F, Banic DM, de Oliveira-Ferreira J 2012. Cells and mediators of inflammation (C-reactive protein, nitric oxide, platelets and neutrophils) in the acute and convalescent phases of uncomplicated Plasmodium vivax and Plasmodium falciparum infection. Mem Inst Oswaldo Cruz 107: 1035-1041.

Medina TS, Costa SP, Oliveira MD, Ventura AM, Souza JM, Gomes TF, Vallinoto AC, Povoa MM, Silva JS, Cunha MG 2011. Increased interleukin-10 and interferon-gamma levels in Plasmodium vivax malaria suggest a reciprocal regulation which is not altered by IL-10 gene promoter polymorphism. Malar J 10: 264.

Mendis K, Sina BJ, Marchesini P, Carter R 2001. The neglected burden of Plasmodium vivax malaria. Am J Trop Med Hyg 64: 97-106.

Mendonça VR, Queiroz AT, Lopes FM, Andrade BB, Barral-Netto M 2013. Networking the host immune response in Plasmodium vivax malaria. Malar J 12: 69.

Miller LH, Baruch DI, Marsh K, Doumbo OK 2002. The pathogenic basis of malaria. Nature 415: 673-679.

MS - Ministério da Saúde Brasil 2010. Guia prático de tratamento da malária no Brasil, MS/Secretaria de Vigilância em Saúde/Departamento de Vigilância Epidemiológica, Brasília, 38 pp.

Murray CJ, Rosenfeld LC, Lim SS, Andrews KG, Foreman KJ, Haring D, Fullman N, Naghavi M, Lozano R, Lopez AD 2012. Global malaria mortality between 1980 and 2010: a systematic analysis. Lancet 379: 413-431.

Ochiel DO, Awandare GA, Keller CC, Hittner JB, Kremsner PG, Weinberg JB, Perkins DJ 2005. Differential regulation of betachemokines in children with Plasmodium falciparum malaria. Infect Immun 73: 4190-4197.

Oliveira-Ferreira J, Lacerda MV, Brasil P, Ladislau JL, Tauil PL, Daniel-Ribeiro CT 2010. Malaria in Brazil: an overview. Malar J 9: 115 .

Othoro C, Lal AA, Nahlen B, Koech D, Orago AS, Udhayakumar V 1999. A low interleukin-10 tumor necrosis factor-alpha ratio is associated with malaria anemia in children residing in a holoendemic malaria region in western Kenya. J Infect Dis 179: 279-282.

Patel U, Gandhi G, Friedman S, Niranjan S 2004. Thrombocytopenia in malaria. J Natl Med Assoc 96: 1212-1214.

Peyron F, Burdin N, Ringwald P, Vuillez JP, Rousset F, Banchereau J 1994. High levels of circulating IL-10 in human malaria. Clin Exp Immun 95: 300-303.

Price RN, Simpson JA, Nosten F, Luxemburger C, Hkirjaroen L, ter Kuile F, Chongsuphajaisiddhi T, White NJ 2001. Factors contributing to anemia after uncomplicated falciparum malaria. $A m J$ Trop Med Hyg 65: 614-622.

Ramharter M, Willheim M, Winkler H, Wahl K, Lagler H, Graninger W, Winkler S 2003. Cytokine profile of Plasmodium falciparumspecific T cells in non-immune malaria patients. Parasite Iтmиnol 25: 211-219.

Schofield L, Mueller I 2006. Clinical immunity to malaria. Curr Mol Med 6: 205-221.

Sina B 2002. Focus on Plasmodium vivax. Trends Parasitol 18: 287289.

Tangpukdee N, Yew HS, Krudsood S, Punyapradit N, Somwong W, Looareesuwan S, Kano S, Wilairatana P 2008. Dynamic changes in white blood cell counts in uncomplicated Plasmodium falciparum and P. vivax malaria. Parasitol Int 57: 490-494.

Taylor WRJ, Widjaja H, Basri H, Ohrt C, Taufik T, Tjitra E, Baso S, Fryauff D, Hoffman SL, Richie TL 2008. Changes in the total leukocyte and platelet counts in Papuan and non Papuan adults from northeast Papua infected with acute Plasmodium vivax or uncomplicated Plasmodium falciparum malaria. Malar J 7: 259.

Ventura AM, Pinto AY, Silva RS, Calvosa VS, Silva Filho MG, Souza JM 1999. Plasmodium vivax malaria in children and adolescents - epidemiological, clinical and laboratory features. J Pediatr 75: 187-194.

Wassmer SC, Taylor T, Maclennan CA, Kanjala M, Mukaka M, Molyneux ME, Grau GE 2008. Platelet-induced clumping of Plasmodium falciparum-infected erythrocytes from Malawian patients with cerebral malaria-possible modulation in vivo by thrombocytopenia. J Infect Dis 197: 72-78.

Weatherall DJ, Miller LH, Baruch DI, Marsh K, Doumbo OK, CasalsPascual C, Roberts DJ 2002. Malaria and the red cell. Hematology Am Soc Hematol Educ Program 2002: 35-57.

Wickramasinghe SN, Abdalla SH 2000. Blood and bone marrow changes in malaria. Baillieres Best Pract Res Clin Haematol 13: 277-299.

Wilson NO, Bythwood T, Solomon W, Jolly P, Yatich N, Jiang Y, Shuaib F, Adjei AA, Anderson W, Stiles JK 2010. Elevated levels of IL-10 and G-CSF associated with asymptomatic malaria in pregnant women. Infect Dis Obstet Gynecol 2010: pii 317430. 